\title{
The regeneration gap
}

\author{
Newts grow new legs, Hydra new heads. These remarkable creatures may \\ hold clues for researchers developing human cellular therapies. But the \\ connections are only now starting to be made. Helen Pearson reports.
}

$\mathrm{T}$ ake one flatworm, chop into 279 pieces and leave for two weeks. Feed occasionally. The result: 279 perfect new worms. The ability of flatworms, or planarians, to regrow an entire body from a handful of cells seems almost miraculous.

Salamanders, starfish, tentacle-waving polyps and zebrafish - many and varied are the organisms that can regenerate new heads, limbs, internal organs or other body parts if the originals are lost or damaged. Unfortunately, people cannot. But over the past few years, researchers studying regenerating creatures have begun to identify the genes, proteins and signalling pathways that underlie these organisms' abilities. This work indicates that the gulf between us and them is not so great. "We have the genes planarians use to regenerate their brain, muscle, their entire head," says Alejandro Sánchez Alvarado of the University of Utah in Salt Lake City.

Millions of dollars are now pouring into work on human stem cells in the hope that they can be used to regrow tissues lost to injury or disease. But Sánchez Alvarado and others who work on naturally regenerating organisms argue that molecular clues gleaned from their research might aid scientists trying to develop human cellular therapies. "We're all looking at the same kind of phenomena," says David Stocum, who studies regeneration in tadpoles of the frog Xenopus laevis at Indiana University-Purdue University in Indianapolis.

Regenerating organisms take one of two approaches to replacing a lost body part. Some, such as flatworms and the polyp Hydra, retain populations of stem cells throughout their lives, which are mobilized when needed. Unlike the 'adult' stem cells found in many of our tissues, which are thought to have a relatively restricted capacity for developing into different cell types, these cells retain the ability to regrow many of the body's tissues.

Other organisms, including newts, segmented worms and zebrafish, convert 'differentiated' adult cells — which have stopped dividing and form part of the skin, muscle or another tissue - back into stem

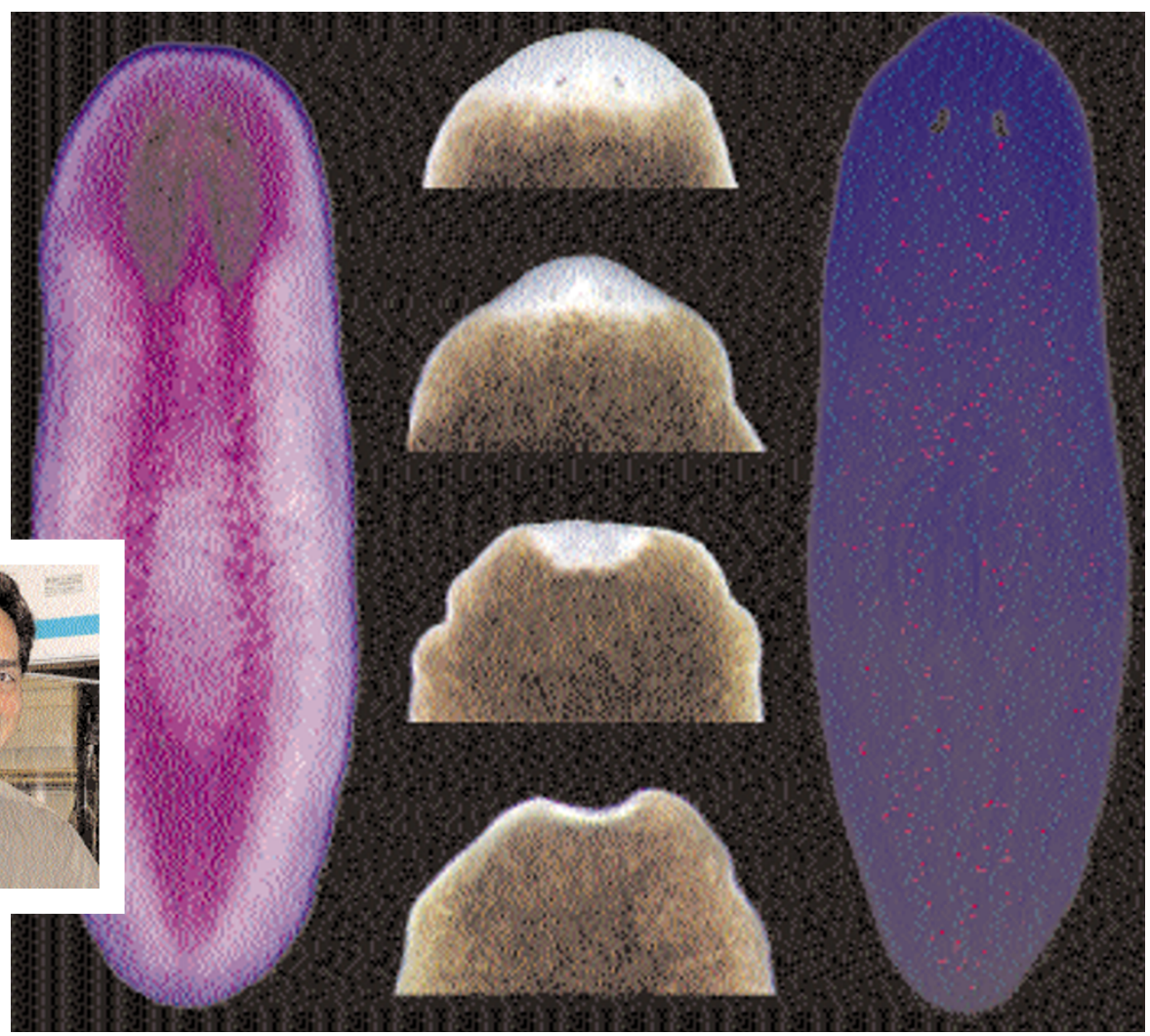

Wonder worms: Alejandro Sánchez Alvarado believes organisms that can regenerate body parts, such as this flatworm shown regrowing its head (centre), could aid human stem-cell research.

cells. This is known as dedifferentiation.

In both types of organism, researchers are now investigating where the cells involved get their instructions from and which genes and proteins are responsible for regeneration. They have been aided by the application of molecular and genetic techniques that are helping to turn these biological curiosities into convenient laboratory organisms (see 'Tools of the trade', opposite).

\section{Working flat out}

The prolific properties of planarian worms make them an ideal starting point for investigating regeneration. A centimetre-long transparent flatworm contains dormant stem cells distributed throughout its body. When damage occurs, cells near the injury site work out where they lie in the body, and carry out very specific local repairs.

Kiyokazu Agata of the RIKEN Center for Developmental Biology in Kobe, Japan, has shown that planarian stem cells rely on signals from neighbouring damaged tissues to work out their location - and hence what repairs are needed ${ }^{1}$. Agata and his colleagues killed the stem cells in one Dugesia japonica worm using X-rays. They then took a section of the irradiated worm, and grafted it upside down into a second worm, replacing the corresponding section of that worm's body.

The intact stem cells neighbouring the grafted tissue produced replacement cell types in the grafted tissue that were consistent with the reversed orientation of the inserted segment. The results convinced Agata, who is now at Okayama University, that cues from differentiated cells in the local environment are essential to instruct stem cells to regenerate correctly. He believes this tenet will also hold for mammalian stem cells: directing them to make desired tissue types will depend on telling them where they are in the body.

Thomas Holstein and his colleagues at 


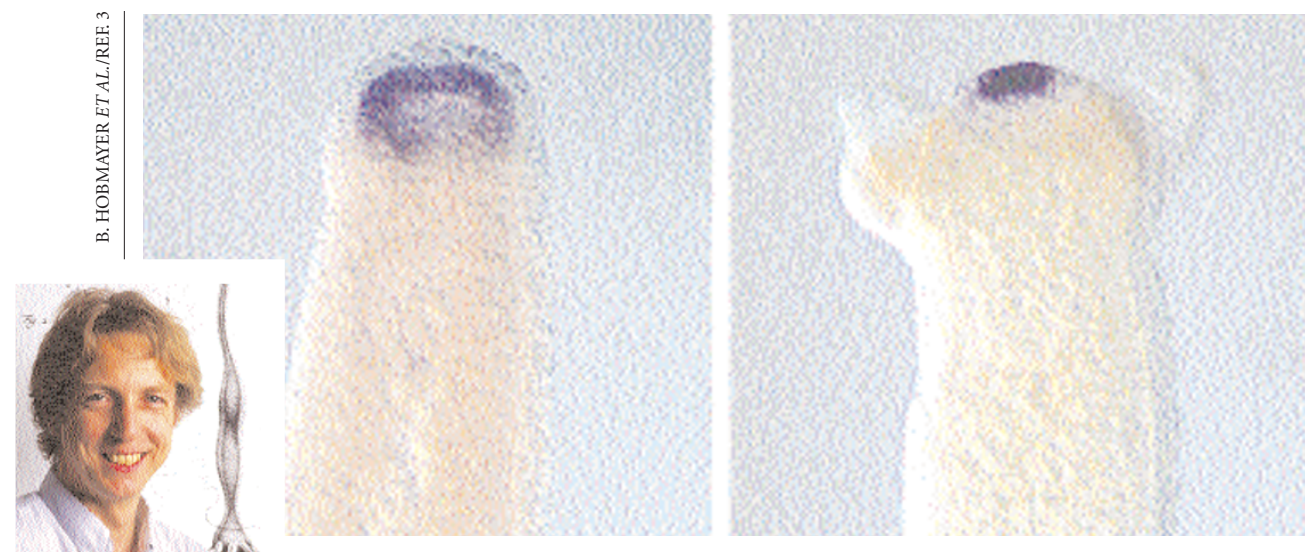

Body plan: Thomas Holstein found Wnt protein (blue stain) is active in Hydra regrowth.

the Technical University of Darmstadt in Germany, meanwhile, are among several research groups showing that the molecules responsible for telling cells their location in the polyp Hydra are those that perform similar jobs in higher animals. But in mammals, they are mainly active during embryological development.

Abundant in freshwater ponds and lakes, Hydra are hollow tubes of cells wrapped around a stomach, with a 'head' of swirling tentacles that captures food. Just like the multiheaded monster of Greek myth, which grew two new heads for every one lopped off, a Hydra can regenerate a new head after decapitation.

\section{Brought to a head}

Its body walls are made up of constantly dividing stem cells in which newborn cells move slowly upwards to form the stinging tentacles, downwards to form the foot, or bud off at the sides to make replica animals. "The basic processes of growth and differentiation are constantly going on," says Holstein. But to develop appropriately, the roaming cells must continuously be told where they are in the organism.

Last year, Holstein's group identified a Hydra member of the Wnt family of secreted proteins, which are involved in setting up the body plan in vertebrates. The researchers showed that this protein is produced just as a baby Hydra begins to bud away from its parent, and at the tip of a decapitated Hydra as its head regrows ${ }^{2}$.

Holstein's team has also established that just a handful of cells from this tip is all that is needed to build a new head. The researchers decapitated several Hydra so that regeneration was under way, mashed the regenerating

\section{ou could create stem cells when you need them, where you want them.}

tips into a pulp of single cells, and then allowed them to form clusters of different sizes. The clusters were added back to clumps of other body cells to find the minimum number of head cells needed to reform a head, which turned out to be about ten ${ }^{3}$.

Other researchers are similarly finding that signalling molecules or regulatory proteins involved in development in higher animals, including mammals, are also involved in regeneration in $\mathrm{Hydra}{ }^{4,5}$. Indeed, biologists working on the polyps believe that the minimal set of such genes commonly used to map out a growing body or limb in complex animals are present in Hydra. "It doesn't matter if you make a tentacle or a tooth," says Brigitte Galliot of the University of Geneva. "The question is similar: how can you make a three-dimensional structure from a pool of stem cells?"

Although much work remains to be done, this question presents an intriguing possibility. Research on Hydra or planarian worms might reveal how to selectively reactivate the genes and proteins that direct early mammalian development, and so induce regeneration in injured or diseased human tissues. And for researchers working on organisms that dedifferentiate adult cells before regenerating, rather than retaining populations of dormant stem cells, such connections with work on mammals are already being made.

\section{Back to the future}

Jeremy Brockes of University College London describes urodele amphibians newts and salamanders - as "champions of regeneration”. Uniquely among vertebrates, they can regrow a wide variety of lost or damaged body parts including limbs, tails, parts of the eye, and even large chunks of the heart. In each case, they achieve this by first dedifferatiating neighbouring cells.

Over the past few years, biologists interested in regenerative medicine have started trying to induce similar developmental reprogramming in mammalian cells ${ }^{6}$. If they could transform any adult cell into a stem cell capable of division and repair, it could bring

\section{Tools of the trade}

The regenerative powers of Hydra polyps have fascinated experimental biologists for more than 250 years. Yet until recently, the processes involved remained unexplained. "The classical literature is chock-full of experiments that need a molecular explanation," says Alejandro Sánchez Alvarado of the University of Utah in Salt Lake City.

One problem is that regenerating organisms do not lend themselves to experimental genetics. Hydra, for example, have a genome as big as that of humans, and refuse to have sex in the lab, making crosses to study the inheritance of traits impossible.

But over the past few years, these extraordinary organisms have been undergoing a renaissance, thanks to the discovery in other species of genes considered to be good candidates for having a role in regeneration, and the advent of techniques for high-throughput analyses of gene activity.

Now, efforts are under way to give regenerating organisms their own genetic toolkits. Two years ago, while he was at the Carnegie Institution of Washington in Baltimore, Sánchez Alvarado's team showed that RNA interference, in which doublestranded molecules of RNA are used to block a specific gene's activity, could be refined for use in flatworms ${ }^{14}$. This will allow researchers to track down the genes involved in

regeneration by systematically

disabling likely candidates.

With Kiyokazu Agata of

Okayama University in Japan,

Sánchez Alvarado is building up a

library of flatworm expressed sequence

tags (ESTs), short DNA sequences from each

of the worms' genes. DNA chips on which these

ESTs are immobilized can be used to investigate

which genes are active during regeneration.

Similar efforts are under way in laboratories

working on Hydra (pictured right). In addition,

there is a Hydra Peptide Project, which is

using chromatography to separate proteins

produced by the polyps. It

then screens for protein

fragments that might be

involved in the signalling

pathways that direct

development and

regeneration by looking for those that

alter patterns of gene activity in Hydra.

The project has so far identified nearly

1,000 candidate peptides ${ }^{15}$.

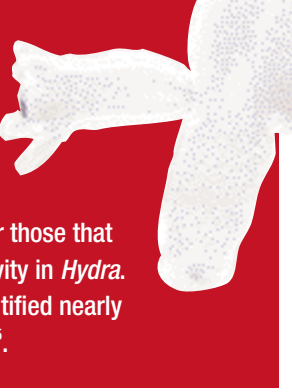

about a medical revolution. So far, they have not had much success, but recent crossovers from work in newts into research on mice have generated a frisson of excitement.

Inspired by newts' capabilities, two research groups have attempted to induce dedifferentiation in mouse muscle. As differentiated adult muscle forms, individual cells stop dividing and fuse together into a myotube, a long muscle fibre containing many cell nuclei. Newt myotubes can reverse 
this process, giving rise to stem cells that can regenerate a limb.

A team led by Peter Schultz of the Scripps Research Institute in San Diego, California, synthesized large libraries of purines, a class of small molecules that commonly bind to proteins and influence a variety of cellular processes. They screened for purines that reversed the differentiation of mouse myotubes, and pulled out one, which they dubbed myoseverin, that caused cells to split off and begin to divide ${ }^{7}$. The compound binds to a component of the myotube's internal skeleton, and might break down the fibre's internal structure.

\section{Muscle switch}

Mark Keating of Harvard Medical School in Boston and his colleagues have concentrated on a gene called $m s x 1$, which encodes a protein that controls the activity of other genes in muscle, and is active both in the regenerating stump of a severed newt leg and in embryonic mouse limbs.

The researchers genetically engineered mouse muscle cells so that the $m s x 1$ gene could be switched off by administering an antibiotic. The team then allowed the cells to develop into myotubes. When the antibiotic was removed, activating $m s x l$, genes that are normally expressed during the differentiation of mouse myotubes were switched off in

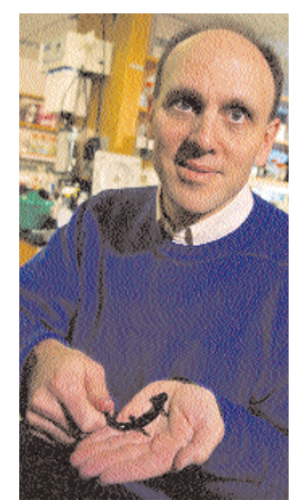

Back on its feet: Mark Keating has identified a gene involved in limb regrowth in newts.
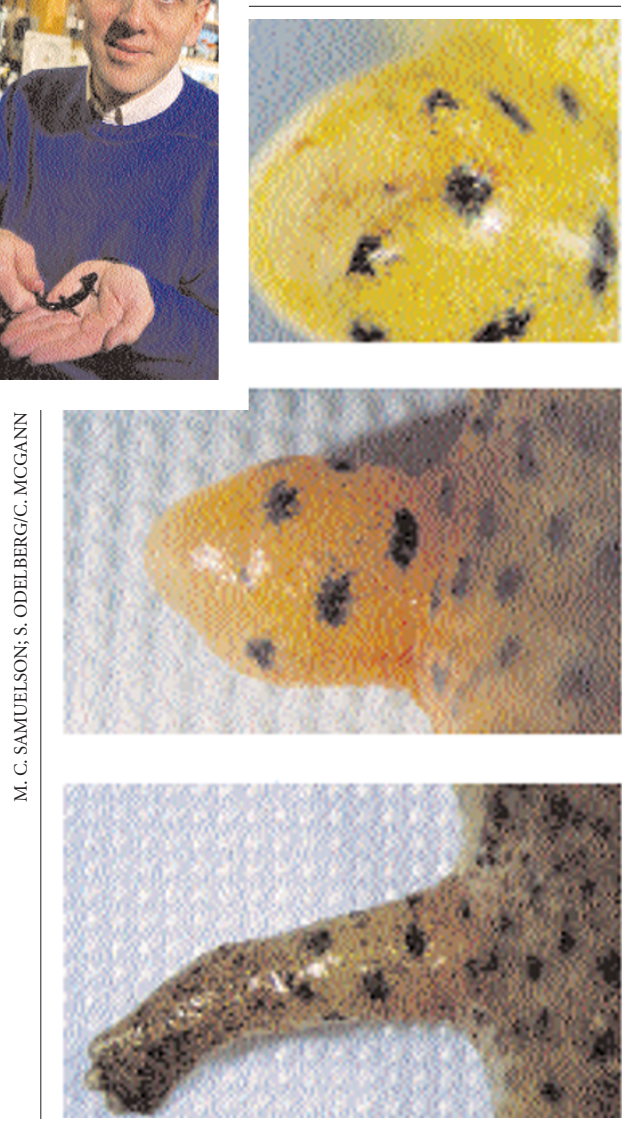

reverse order, and individual cells began to break off from the myotubes and divide ${ }^{8}$. Furthermore, these dedifferentiated cells, when plied with appropriate growth factors, could form fat, bone and cartilage as well as muscle. "They have the ability to go back in time," says Keating.

Keating and Brockes have since been working out what normally stops mammalian muscle from undergoing dedifferentiation. Brockes believes that the block arises from a failure to activate the appropriate cellular signalling pathways inside mammalian myotubes. But by merging newt and mouse muscle cells to form hybrid myotubes, his team has found that the mouse nuclei can be induced to start copying their DNA - a prelude to cell division?

Keating, meanwhile, has found that liquidized extracts from regenerating newt myotubes can trigger the dedifferentiation of mammalian myotubes ${ }^{10}$, suggesting that a protein present in a newt limb stumps triggers the dormant pathways. "It may be all that's required to get regeneration," Keating speculates. If that elusive protein can be tracked down, he suggests, "you could create stem cells when you need them, where you want them."

Some evidence has emerged that certain strains of mouse are unusually predisposed to regeneration. Ellen Heber-Katz
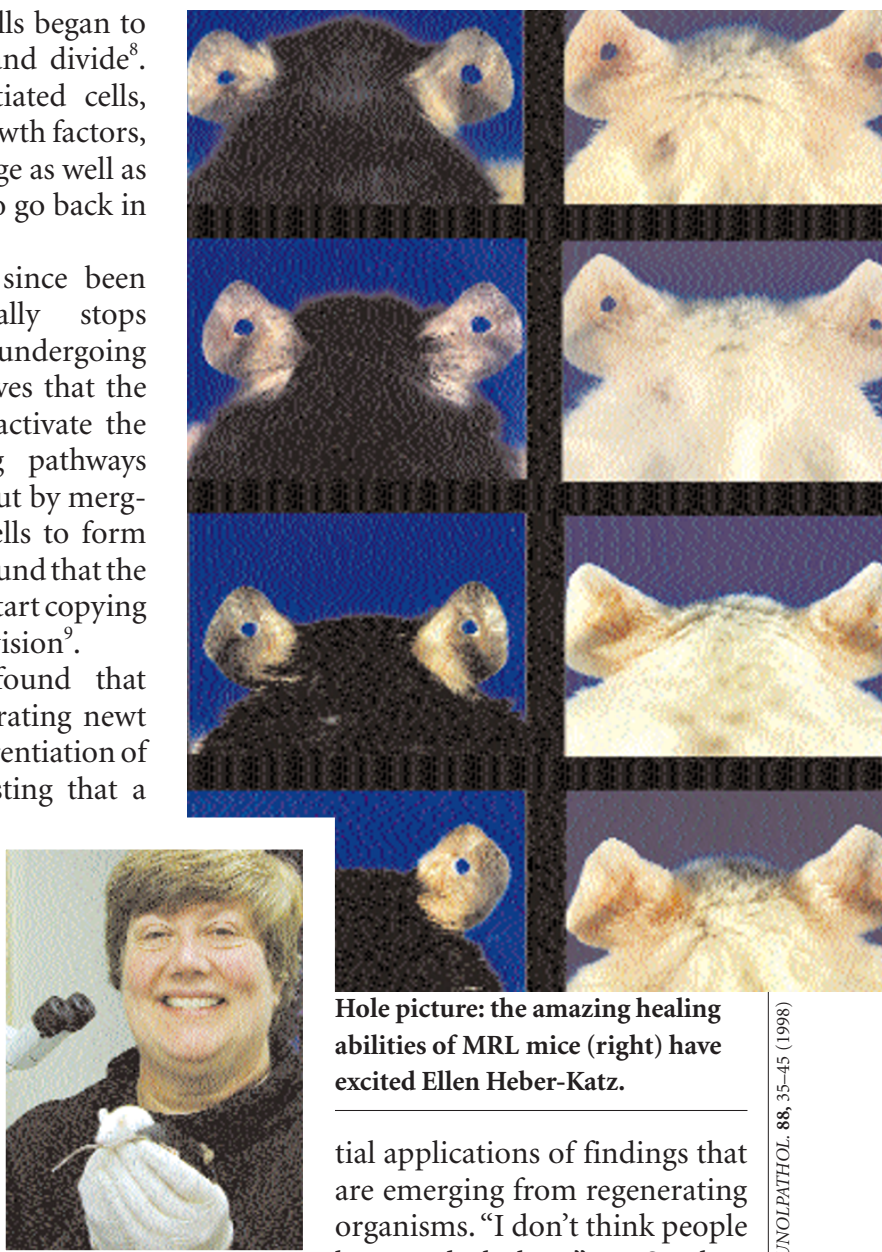
of the Wistar Institute in Philadelphia punched 2-millimetre holes in the ears of members of a laboratory strain called MRL — a standard technique used to tell individuals apart. Three weeks later, there were no holes and no scars ${ }^{11}$. Although such healing is usual in rabbits, it had never before been seen in mice. "I was virtually jumping up and down," says Heber-Katz. "Clearly these mice can do things that others can't."

\section{Growth potential}

Since stumbling on this quirk, Heber-Katz has studied the MRL strain's regenerative capacities. When one chamber of their heart is frozen, the mice take only two months to recover normal working heart muscle ${ }^{12}$. In other strains, the damaged muscle does not recover. MRL mice appear to form less scar tissue than other strains, and this may be their secret. Scar tissue inhibits regeneration, Heber-Katz believes. She suspects that, in MRL mice, enzymes that break down scar tissue may be overactive. Although her team has shown in studies of the trait's inheritance that several genes must underlie MRL's regenerative abilities $^{13}$, these have yet to be identified.

Despite the upsurge of interest in mammalian stem-cell research and regenerative medicine, relatively few researchers working in this area seem aware of the poten- have made the leap," says Stephen Johnson, who studies the regeneration of zebrafish fins at the Washington University School of Medicine in St Louis, Missouri.

Diane Krause of Yale University, who works on the bone marrow stem cells that give rise to blood cells, agrees that researchers trying to develop the field of regenerative medicine should start paying more attention to the work of biologists studying newts, Hydra and other champions of regeneration. "Do I follow them? No. Should I? Yes."

Helen Pearson works in Nature's science writing team.

1. Kato, K., Orii, H., Watanabe, K. \& Agata, K. Dev. Biol. 233, 109-121 (2001)

2. Hobmayer, B. et al. Nature 407, 186-189 (2000).

3. Technau, U. et al. Proc. Natl Acad. Sci. USA 97, 12127-12131 (2000).

4. Smith, K. M., Gee, L. \& Bode, H. R. Development 127, 4743-4752 (2000)

Guachat, D. et al. Proc. Natl Acad. Sci. USA 97, 4493-4498 (2000).

6. Aldhous, P. Nature 410, 622-625 (2001).

7. Rosania, G. R. et al. Nature Biotechnol. 18, 304-308 (2000).

8. Odelberg, S. J., Kollhoff, A. \& Keating, M.T. Cell 103, 1099-1109 (2000).

9. Velloso, C. P., Simon, A. \& Brockes, J. P. Curr. Biol. 11, 855-858 (2001).

10. McGann, C. J., Odelberg, S. J. \& Keating, M. T. Proc. Natl Acad. Sci. USA 98, 13699-13704 (2001).

11. Clark, L. D., Clark, R. K. \& Heber-Katz, E. Clin. Immunol. Immunopathol. 88, 35-45 (1998).

12. Leferovich, J. M. et al. Proc. Natl Acad. Sci. USA 98, 9830-9835 (2001).

13. McBrearty, B. A., Clark, L. D., Zhang, X.-M., Blankenhorn, E. P. \& Heber-Katz, E. Proc. Natl Acad. Sci. USA 95, 11792-11797 (1998). 14. Sánchez Alvarado, A. \& Newmark, P. A. Proc. Natl Acad. Sci. USA 96, 5049-5054 (1999).

15. Bosch, T. C. G. \& Fujisawa, T. BioEssays 23, 420-427 (2001). 